\title{
Growth, Development, and Response of Peach Somaclones to the Root-knot Nematode, Meloidogyne incognita
}

\author{
Ghazala P. Hashmi ${ }^{1}$, F.A. Hammerschlag ${ }^{2}$, and R.N. Huettel ${ }^{3}$ \\ Beltsville Agricultural Research Center, Agricultural Research Service, U.S. Department ofAgriculture, \\ Beltsville, MD 20705
}

L.R. Krusberg ${ }^{4}$

Department of Botany, University, College Park, MD 20742-5815

Additional index words. in vitro screening, Meloidogyne incognita, nematode resistance, Prunus persica

\begin{abstract}
Somaclonal variation has been reported in many plant species, and several phenotypic and genetic changes, including pathogen and pest resistance, have been described. This study was designed to evaluate somaclonal variation in peach [Prunus persica (L.) Batsch] regenerants in response to the root-knot nematode, Meloidogyne incognita (Kofoid \& White) Chitwood. Regenerants SH-156-1, SH-156-7, SH-156-11, and SH-156-12, derived from 'Sunhigh' (susceptible) embryo no. 156, and regenerants RH-30-1, RH-30-2, RH-30-4, RH-30-6, RH-30-7, and RH-30-8, derived from 'Redhaven' (moderately resistant) embryo no. 30, were screened in vitro for resistance to the root-knot nematode. Under in vitro conditions, fewest nematodes developed on regenerants SH-156-1 and SH-156-11, 'Redhaven', and all 'Redhaven' embryo no. 30 regenerants. The most nematodes developed on 'Sunhigh', 'Sunhigh' seedlings (SHS), and regenerant SH-156-7. Nematodes did not develop on 'Nemaguard'. In greenhouse tests, fewer nematodes developed and reproduced on the no. 156-series regenerants than on 'Sunhigh'. Under in vitro conditions, significant differences among uninfected (control) regenerants, cultivars, and rootstock 'Nemaguard' were observed for shoot height and fresh root weights. Significant differences were also observed among infected regenerants, cultivars, and 'Nemaguard' for these characteristics, but differences were not observed between control and infected regenerants. Different concentrations of $\alpha$ - naphthaleneacetic acid in half-strength Murashige and Skoog salt medium induced rooting of two peach cultivars, one rootstock, and four regenerants.
\end{abstract}

A long generation time and narrow germplasm base has impeded progress in generating peach trees with significant levels of pathogen and pest resistance and more efficient growth habits (Scorza and Hammerschlag, 1992; Scorza and Okie, 199 1). Recent advances in cellular and molecular approaches to crop improvement could facilitate peach improvement by generating new sources of variation that arise spontaneously in cell culture or are specifically engineered (Burrows and Jones, 1993). Regenerating plants from organs, tissues, or cells is effective for obtaining somaclonal variants (Larkin and Scowcroft, 1981) with enhanced disease resistance (Daub, 1986; Hammerschlag, 1984, 1992) and altered growth habit (Reisch, 1983). Several examples of disease-resistant crop plants obtained by screening regenerants or their progenies at the whole-plant level without in vitro preselection include alfalfa (Medicago sativa L.) for resistance to Verticillium albo-atrum (Latunde-Dada and Lucas, 1983), celery (Apium graveolens L.) to Fusarium oxysporum (Heath-Pagliuso et al., 1988), and tobacco (Nicotiana tabacum L.) to Phytophthoraparasitica pv. nicotianae and Pseudomonas solanacearum (Daub and Jenns, 1989). Alter-

Received for publication 29 Mar. 1995. Accepted for publication 10 July 1995. Use of a company or product name does not imply approval or recommendation of the product to the exclusion of others, which may also be suitable. The cost of publishing this paper was defrayed in part by the payment of page charges. Under postal regulations, this paper therefore must be hereby marked advertisement solely to indicate this fact.

'Former graduate research assistant, Univ. of Maryland. Present address: Dept. of Entomology, Cook College, Rutgers Univ., P.O. Box 231, New Brunswick, NJ 08903.

${ }^{2}$ Plant physiologist, Plant Molecular Biology Laboratory. To whom reprint requests should be addressed.

${ }^{3}$ Microbiologist, Nematology Laboratory. Present address: USDA/APHIS PPQPRP, Federal Bldg., Rm. 816, 6505 Belcrest Rd., Hyattsville, MD 20782.

${ }^{4}$ Professor. ations in growth habit of somaclones have been reported for tobacco (Berlyn, 1980) and potato (Solanum tuberosum L.) (Thomas, 1981). Little work has been done on using this approach to generate nematode-resistant plants. In the work of Evans et al. (1986), no plants resistant to the potato cyst nematode (Globodera rostochiensis Behrens and G. pallida Behrens) were obtained after screening 167 clones derived from cell cultures. Larkin et al. (1990) were able to introgress resistance to the cereal cyst nematode (Heterodera avenue Wollenweber) from rye (Secale cereale L.) to wheat by regenerating plants from wheat (Triticum aestivum L.) callus cultures containing the rye (6R) chromosome.

Until recently, only conventional breeding techniques were used to improve peaches genetically. Tissue-culture technologies developed to propagate known scion cultivars (Hammerschlag et al., 1987) and to regenerate peach plants from cell cultures reliably (Hammerschlag et al., 1985) have led to identifying somaclonal variants of peach with increased levels of bacterial leaf-spot resistance (Hammerschlag, 1988, 1990). Resistance to leaf spot has been stable through propagation over time and under field conditions (Hammerschlag et al., 1994; Ritchie et al., 1993). Bacterial canker-resistant plants were also obtained by screening unselected peach regenerants for resistance to Pseudomonas syringae pv. syringae (Hammerschlag and Ognjanov, 1990). Recently, the response of several peach genotypes to root-knot nematode under in vitro conditions corresponded with the response to root-knot nematode under field conditions (Huettel and Hammerschlag, 1993). It would be of value to use such a system as a prescreen to identify new sources of variation (somaclonal; variants) with respect to root-knot nematode resistance. Although conventional breeding methods have generated several important root-knot nematode-resistant rootstocks (Sherman et al., 1981), they have been of limited use in the southeastern United States 
because they are not cold tolerant (Layne, 1974) or are susceptible to peach-tree short life (Ritchie and Clayton, 1981).

The objective of the present study was to determine if peach regenerants exhibit somaclonal variation for growth, development, and resistance to the root-knot nematode, Meloidogyne incognita and whether somaclonal variation is expressed in vitro.

\section{Materials and Methods}

Plant material. The plants used were root-knot nematodesusceptible 'Sunhigh' peach, moderately tolerant 'Redhaven', resistant rootstock 'Nemaguard' , regenerants SH-156-1, SH-1.56 7, SH-156-11, and SH-156-12 derived from callus of 'Sunhigh' embryo no. 156, and RH-30-1, RH-30-2, RH-30-4, RH-30-6, RH30-7, and RH-30-8 derived from callus of 'Redhaven' embryo no. 30 (Hammerschlag, 1990; Hammerschlag et al., 1985). Regenerants and axillary shoots of 'Sunhigh', 'Redhaven', and 'Nemaguard', obtained from actively growing greenhouse-grown plants, were micropropagated and rooted as described by Hammerschlag et al. (1987). Plantlets to be inoculated with $M$. incognita were transferred to one-fourth strength Murashige and Skoog (MS) salts medium (Murashige and Skoog, 1962) without growth regulators and supplemented with $2 \%$ sucrose and $0.6 \%$ Phytagar (Gibco, Grand Island, N.Y.). Peach seeds were obtained from fruit of openpollinated 'Sunhigh' trees as described by Hammerschlag (1990), and for germination were plated onto quarter-strength MS medium and incubated in the dark at $4 \mathrm{C}$ for 3 months. Germinated seeds were transferred to fresh quarter-strength MS medium and placed at $25 \mathrm{C}$ under a $16-\mathrm{h}$ photoperiod provided by cool-white fluorescent lamps at $40 \mu \mathrm{mol} \cdot \mathrm{m}^{-2} \cdot \mathrm{s}^{-1}$. 'Sunhigh' seedlings (SHSs) were inoculated as described below.

Rooting studies. For rooting studies, in vitro-propagated regenerants and cultivars were transferred to half-strength MS medium supplemented with $2 \%$ sucrose, 0.6\% Phytagar, 2.84, 1.42 , or $0.56 \mu \mathrm{M} \alpha$ - naphthaleneacetic acid (NAA), and the following in $\mathrm{mg} \cdot \mathrm{liter}^{-1}$ : 0.4 thiamine $\cdot \mathrm{HCl}, 100$ myo-inositol, 0.05 nicotinic acid, 0.05 pyridoxine $\cdot \mathrm{HCl}$, and $0.01 p$-aminobenzoic acid. All plants were incubated at $25 \mathrm{C}$ under a $16-\mathrm{h}$ photoperiod provided by cool-white fluorescent lamps at $40 \mu \mathrm{mol} \cdot \mathrm{m}^{-2} \cdot \mathrm{s}^{-1}$. The percentage rooting was recorded after 10 days. The experiment was replicated three times with 15 plants/replicate.

Nematode inoculum. Meloidogyne incognita was obtained from sterile root explants of 'Rutgers' tomato (Lycopersicon esculenturn Mill.) maintained on B5 medium (Gamborg et al., 1976). Egg masses were hand picked, and eggs were hatched at $28 \mathrm{C}$ in 12 -well plates containing $2 \mathrm{ml}$ of sterile distilled water per well. Second-stage juveniles (J2) were collected aseptically and counted after $48 \mathrm{~h}$.

Inoculation procedure. The agar surface surrounding the base of a peach plantlet or SHSs (with roots about 2-cm long) was infested with $0.1 \mathrm{ml}$ of a sterile aqueous suspension containing 200 freshly hatched and active $\mathrm{J} 2$. Plants were incubated at $25 \mathrm{C}$ under a $16-\mathrm{h}$ photoperiod of about $40 \mu \mathrm{mol} \cdot \mathrm{m}^{-2} \cdot \mathrm{s}^{-1}$ irradiance provided by cool-white fluorescent lamps.

Screening procedures. Data on plant growth and nematode development were collected after 5 weeks of incubation. For growth characteristics, plants were cut at the base, and shoot heights, shoot fresh weights, and root fresh weights were recorded. For nematode development, the root system was removed and stained in $0.05 \%$ cotton blue in a solution of 1 distilled water : 1 lactic acid : 1 glycerol (by volume). After $24 \mathrm{~h}$, roots were gently crushed and the numbers of nematodes developing inside the roots were counted using a dissecting microscope. Only swollen nematodes (third- and fourth-stage juveniles (J3/J4) and mature fe- males) inside the roots were counted. Although egg masses were produced, eggs were not counted because of the difficulty of recovering all the eggs from the tissue-culture media.

The experiment was set up according to a randomized block design with three replicates and five plants of each regenerant and cultivar per replicate. Uninoculated plants served as controls.

Greenhouse studies. Axillary shoots of peach regenerants SH156-1, SH-156-7, SH-156-11, SH-156-12, and 'Sunhigh' were rooted, acclimatized (Hammerschlag et al., 1987), and grown in the greenhouse. Plants 20 to $30 \mathrm{~cm}$ tall were transferred into $15-$ pm-diameter plastic pots (one plant per pot) and the 3 soil : 1 peat : 1 perlite mixture (by volume) was infested with a suspension of 10,000 freshly collected eggs and 52 of $M$. incognita obtained from greenhouse-grown plants of 'Rutgers' tomato as follows: roots were rinsed with tap water to remove soil, then immersed in $0.5 \%$ $\mathrm{NaOCl}$ for $45 \mathrm{sec}$ (to release eggs from the root surface), and eggs were extracted by differential sieving and sugar flotation (McClure et al., 1973). Egg suspensions in a $0.05 \%$ chlorhexidine diacetate (Sigma Chemical Co., St. Louis) solution were aerated overnight. The inoculum was placed in four 4- to 5-cm-deep holes located 4 $\mathrm{cm}$ from the base of the plant. Plants were watered daily, or as needed, and fertilized once a week with 100 ppm Peters 20-20-20 fertilizer (W.R. Grace \& Co., Fogelsville, Pa.). Because of the rapid growth of the peach plants, each plant was pruned about 30 $\mathrm{cm}$ from the top 6 weeks after soil infestation with nematodes. All pots were arranged in a randomized block design with two replicates and three plants of each regenerant/cultivar per replicate. Uninoculated plants were kept as controls.

Nematodes per plant were counted 100 days after infestation. Nematodes in the soil were obtained by transferring soil from the pots to a large bucket. Roots from each plant were immersed in $0.5 \% \mathrm{NaOCl}$ for $45 \mathrm{sec}$ in a second bucket. The contents of both buckets were combined and eggs were extracted by differential sieving and sugar flotation as mentioned above. Eggs were suspended in $250 \mathrm{ml}$ of water and eggs in a l-ml subsample were counted. Nematodes inside roots were counted as described above.

Data analysis. All experiments were conducted at least three times (except greenhouse studies, which were conducted twice) and data were combined for analysis. Analysis of variance (ANOVA) was performed on nematode counts and data on plant growth characteristics, and treatment means were separated by LSD at $P=0.05$.

\section{Results}

Rooting studies. Differences in rooting were observed among peach regenerants and cultivars on half-strength MS salts medium containing different concentrations of NAA (Table 1). All regenerants rooted best on medium containing $1.42 \mu \mathrm{M}$ of NAA, except SH-156-12, which rooted similarly on all concentrations. Of the regenerants, the best percentage of rooting was achieved by SH-156-7 (100\%) and SH-156-11 (88\%). Root-knot nematoderesistant rootstock 'Nemaguard' rooted $100 \%$ on all media tested. For 'Sunhigh' shoots, the highest percentage of rooting occurred on $1.42 \mu \mathrm{M}$ NAA, whereas $2.84 \mu \mathrm{M}$ NAA was optimum for 'Redhaven'.

Growth characters. Under in vitro conditions, means for all three growth characters (shoot height, shoot fresh weight, and root fresh weight) were similar for infected and uninfected plants of each 'Sunhigh' embryo no. 156 regenerant (Table 2) and, overall, infection with $M$. incognita did not suppress any of the growth characters $(P=0.05)$. Some significant differences among controls and among infected regenerants, cultivars, and rootstock 
Table 1. Effect of three concentrations of $\alpha$ - naphthaleneacetic acid (NAA) on peach shoot rooting in vitro.

\begin{tabular}{lccc}
\hline \hline $\begin{array}{l}\text { Cultivar/ } \\
\text { rootstock/ }\end{array}$ & \multicolumn{2}{c}{$\begin{array}{c}\text { Rooting percentage } \pm \mathrm{SE}^{\mathrm{y}} \\
\mu \mathrm{M} \text { NAA }\end{array}$} \\
\cline { 2 - 4 } regenerant $^{2}$ & 2.84 & 1.42 & 0.56 \\
\hline Redhaven & $60 \pm 1.0$ & $37 \pm 0.7$ & $50 \pm 0.9$ \\
Sunhigh & $77 \pm 1.0$ & $100 \pm 0.0$ & $80 \pm 1.4$ \\
Nemaguard & $100 \pm 0.0$ & $100 \pm 0.0$ & $100 \pm 0.0$ \\
$156-1$ & $69 \pm 1.5$ & $73 \pm 1.9$ & $60 \pm 1.2$ \\
$156-7$ & $89 \pm 0.9$ & $100 \pm 0.0$ & $56 \pm 1.2$ \\
$156-11$ & $82 \pm 1.4$ & $88 \pm 1.1$ & $74 \pm 0.7$ \\
$156-12$ & $77 \pm 0.6$ & $76 \pm 1.1$ & $75 \pm 1.8$
\end{tabular}

${ }^{\overline{2}}$ Scions 'Redhaven' and 'Sunhigh' and rootstock Nemaguard; 156-1 through 156-12 are peach regenerants derived from callus of 'Sunhigh' embryo no. 156.

y All values are means $\left({ }^{*} \mathrm{SE}\right)$ of three replicates with 15 plants/replicate.

'Nemaguard' were observed. For example, mean shoot heights were significantly higher for infected SH-156-11 and 'Nemaguard' than for the other regenerants and significantly lower for infected regenerant SH-156-1 than for regenerants SH-156-7, SH-156-12, 'Nemaguard', 'Sunhigh', and 'Redhaven'. Fresh root weights of infected 'Sunhigh' and SH-156-12 were significantly higher than for rootstock 'Nemaguard', 'Redhaven', and regenerants SH-1561 and SH-156-11. Shoot height for uninfected regenerant SH-1561 was significantly lower than for SH-156-11, 'Sunhigh', and 'Nemaguard', and root weight for uninfected regenerants SH-15612 was significantly greater than for 'Sunhigh', SH-156-11, and SH-156-1. In some cases, differences in growth among regenerants and cultivars were evident only when comparing infected plants. For example, mean shoot height for uninfected plants of regenerant SH-156-1 was similar to that of SH-156-7 and 'Redhaven', whereas mean shoot height for infected SH-156-1 plants was significantly lower than that for SH-156-7 and 'Redhaven'.

Nematode development. Development of $M$. incognita in vitro was studied on 'Sunhigh' and regenerants SH-156-1, SH-156-7, SH-156-11, and SH-156-12 and on 'Redhaven' and regenerants RH-30-1, RH-30-2, RH-30-4, RH-30-6, RH-30-7, and RH-30-8. The no. 156 series regenerants varied significantly in response to nematode infection (Table 3). Fewest nematodes developed in the root systems of SH-156-11, and 'Redhaven', whereas the most developed on regenerant SH-156-7, 'Sunhigh', and SHSs. The response of regenerants $\mathrm{SH}-156-1$ and $\mathrm{SH}-156-12$ was intermediate between the response of Sunhigh' and 'Redhaven'. Nematode development was similar on 'Redhaven' and regenerants from 'Redhaven' embryo no. 30. When individual SHSs were examined, none was more resistant than 'Redhaven' or regenerants $\mathrm{SH}$ 156-1 and SH-156-11 (Table 3). No nematode development was observed on resistant rootstock 'Nemaguard'.

Greenhouse studies. Development of $M$. incognita was studied On regenerants SH-156-1, SH-156-7, and SH-156-12 and 'Sunhigh' under greenhouse conditions (Table 4). More mature females matured in roots of 'Sunhigh' than in the roots of any of the no. 156-series regenerants. Although more J3/J4 were observed in the root system of SH-156-1 than in 'Sunhigh' and the other no. 156 regenerants, significantly fewer mature females and eggs developed in SH-156-1 than in 'Sunhigh'. The number of eggs per milliliter of subsample was 0.2 and 0.4 times the number of mature females for SH-156-1 and SH-156-7, respectively, whereas, the number of eggs was 2.4 and 4.0 times that of females for 'Sunhigh' and $\mathrm{SH}-156-12$, respectively. Meloidogyne incognita egg produc-

Table 2. Average shoot height, fresh shoot weight, and fresh root weight of in vitro-grown peach regenerants and susceptible 'Sunhigh', moderately resistant 'Redhaven', and resistant rootstock Nemaguard, 5 weeks after inoculation with 200 freshly hatched juveniles of Meloidogyne incognita.'

\begin{tabular}{lccc}
\hline \hline $\begin{array}{l}\text { Cultivar/ } \\
\text { rootstock/ } \\
\text { regenerant }^{y}\end{array}$ & $\begin{array}{c}\text { Shoot ht } \\
(\mathrm{mm})\end{array}$ & $\begin{array}{c}\text { Shoot fresh } \\
\text { wt (mg) }\end{array}$ & $\begin{array}{c}\text { Root fresh } \\
\text { wt (mg) }\end{array}$ \\
\hline Nemaguard-I & $49.4 \mathrm{a}$ & $330 \mathrm{~cd}$ & $460 \mathrm{bc}$ \\
Nemaguard-C & $34.3 \mathrm{bc}$ & $390 \mathrm{bc}$ & $410 \mathrm{bc}$ \\
Sunhigh-I & $34.8 \mathrm{bc}$ & $580 \mathrm{a}$ & $690 \mathrm{a}$ \\
Sunhigh-C & $34.4 \mathrm{bc}$ & $470 \mathrm{ab}$ & $290 \mathrm{~cd}$ \\
Redhaven-I & $33.9 \mathrm{bc}$ & $330 \mathrm{~cd}$ & $320 \mathrm{~cd}$ \\
Redhaven-C & $31.8 \mathrm{~cd}$ & $270 \mathrm{~d}$ & $190 \mathrm{~d}$ \\
SH-156-12-I & $29.9 \mathrm{~cd}$ & $270 \mathrm{~d}$ & $560 \mathrm{a}$ \\
SH-156-12-C & $32.1 \mathrm{~cd}$ & $240 \mathrm{~d}$ & $490 \mathrm{ab}$ \\
SH-156-11-I & $42.3 \mathrm{ab}$ & $360 \mathrm{bcd}$ & $460 \mathrm{bc}$ \\
SH-156-11-C & $38.8 \mathrm{bc}$ & $330 \mathrm{~cd}$ & $320 \mathrm{~cd}$ \\
SH-156-7-I & $32.8 \mathrm{c}$ & $280 \mathrm{~d}$ & $480 \mathrm{ab}$ \\
SH-156-7-C & $30.2 \mathrm{~cd}$ & $330 \mathrm{~cd}$ & $370 \mathrm{bcd}$ \\
SH-156-1- & $25.7 \mathrm{~d}$ & $310 \mathrm{~cd}$ & $360 \mathrm{bcd}$ \\
SH-156-1-C & $26.1 \mathrm{~d}$ & $290 \mathrm{~cd}$ & $290 \mathrm{~cd}$
\end{tabular}

${ }^{\bar{z}}$ All values are means of three replicates, with five plants per replicate. Means within columns followed by same letter are not different $(\mathrm{P}=0.05)$ according to LSD. $\mathrm{I}=$ nematode inoculated, $\mathrm{C}=$ uninoculated control.

'Regenerants from callus of 'Sunhigh' embryo no. 156. 
Table 3. Response of 'Sunhigh' and 'Redhaven' peach, 'Sunhigh' regenerants, and seedlings to Meloidogyne incognita infection in vitro. ${ }^{2}$

\begin{tabular}{lccc}
\hline \hline $\begin{array}{l}\text { Cultivar/ } \\
\text { regenerant }\end{array}$ & $\begin{array}{c}\text { Avg no. of } \\
\text { mature females }\end{array}$ & $\begin{array}{c}\text { Sunhigh } \\
\text { seedlings }\end{array}$ & $\begin{array}{c}\text { Avg no. of } \\
\text { mature females }\end{array}$ \\
\hline Sunhigh & $23 \mathrm{a}$ & SHS-08 & 15 \\
Redhaven & $5 \mathrm{~d}$ & SHS-04 & 16 \\
SH-156-11 & $10 \mathrm{~cd}$ & SHS-07 & 16 \\
SH-156-1 & $12 \mathrm{bc}$ & SHS-06 & 18 \\
SH-156-12 & $16 \mathrm{~b}$ & SHS-03 & 19 \\
SH-156-7 & $26 \mathrm{a}$ & SHS-12 & 19 \\
& & SHS-15 & 27 \\
& & SHS-16 & 27 \\
& & SHS-17 & 33 \\
& & SHS-05 & 38 \\
& & SHS-10 & 38 \\
& & SHS-13 & 39 \\
& & SHS-09 & 42 \\
& & SHS-18 & 49 \\
& & SHS-01 & 51
\end{tabular}

${ }^{7}$ Numbers of nematodes developed on all regenerants, 'Sunhigh' and 'Redhaven' are means of three replicates with five plants in each replicate. Means followed by the same letter are not significantly different $(P=0.05)$ according to LSD.

${ }^{y}$ Regenerant from callus of 'Sunhigh' embryo no. 156.

tion was significantly higher on the susceptible control 'Rutgers' tomato than on 'Sunhigh' peach or any of the peach regenerants.

\section{Discussion}

The results of this study demonstrate the presence of somaclonal variation among regenerated peach plants as shown by the significant differences in rooting, growth characteristics, and nematode development among plants regenerated from the same 'Sunhigh' embryo. Somaclonal variation was observed in vitro and under greenhouse conditions. Although the response of the somaclonal variants to root-knot nematode under field conditions has yet to be determined, our previous study with peach cultivars (Huettel and Hammerschlag, 1993) indicated that response in vitro 5 weeks after infection could forecast reactions of peach to $M$. incognita under field conditions. This in vitro system, which can serve as a prescreen (and not replace field testing), should be extremely useful because evaluations are performed after 5 weeks compared a minimum of 3 years required for field studies (Huettel and Hammerschlag, 1993). Thus, many regenerants could be evaluated and only the most promising transferred to the field.
The observed differences in the amount of variation in $M$. incognita resistance among regenerants from 'Sunhigh' embryo no. 156 and 'Redhaven' embryo no. 30 suggest a genotype effect. Previous studies with peach regenerants demonstrated that the degree of somaclonal variation with respect to bacterial leaf spot was genetically determined (Hammerschlag, 1990). In addition, other studies with different plant species have indicated that the amount of variation observed is genotype-dependent (Daub and Jenns, 1989; McCoy et al., 1982); this may explain the failure to obtain variant lines in some studies (Fassuliotis and Bhatt, 1982; Gavazzi et al., 1987). Thus, to isolate somaclonal variants with a desired trait successfully, the best strategy may be to obtain regenerants derived from many genotypes (Daub, 1986; Hammerschlag, 1992).

Previous studies have suggested that the level of disease resistance in the source material will determine the level of resistance in the somaclonal variants. For example, a much higher frequency of plants resistant to fusarium yellows was obtained from regenerants of a moderately resistant celery cultivar than from a highly susceptible cultivar (Wright and Lacy, 1988). In studies with peach (Hammerschlag, 1988, 1990), a very high level of

Table 4. Development of Meloidogyne incognita on 'Sunhigh' peach, three peach regenerants, and susceptible 'Rutgers' tomato 100 days after nematode inoculation in the greenhouse. ${ }^{2}$

\begin{tabular}{lcrr}
\hline \hline Cultivar/ & & Nematodes (no.) & \\
\cline { 2 - 4 } regenerant & $\mathrm{J} 3 / \mathrm{J} 4 \mathrm{y}$ & Mature females $^{\mathrm{y}}$ & Eggsx \\
\hline Sunhigh & $40 \mathrm{~b}$ & $181 \mathrm{~b}$ & $725 \mathrm{~b}$ \\
SH-156-1 & $78 \mathrm{a}$ & $68 \mathrm{c}$ & $13 \mathrm{~d}$ \\
SH-156-7 & $44 \mathrm{~b}$ & $99 \mathrm{c}$ & $39 \mathrm{~d}$ \\
SH-156-12 & $39 \mathrm{~b}$ & $91 \mathrm{c}$ & $219 \mathrm{c}$ \\
Rutgers & $85 \mathrm{a}$ & $500 \mathrm{a}$ & $4857 \mathrm{a}$
\end{tabular}

${ }^{2}$ All values are means of two replicates with three plants in each replicate inoculated with 10,000 M. incognita juveniles plus eggs.

Means within columns followed by the same letter are not different $(P=0.05)$ according to LSD.

${ }^{y}$ Mean of five 1 -g subsamples of roots per plant; J3/J4 = third- and fourth-stage juveniles.

${ }^{\mathrm{x}}$ Mean of three 1-ml subsamples per plant from an egg suspension in $250 \mathrm{ml}$ of water. 
baeterial leaf-spot resistance was observed in a regenerant from a moderately resistant cultivar, whereas only moderate levels were observed in regenerants from a highly susceptible cultivar. In this study, we observed an increase in resistance to $M$. incognita among 'Sunhigh' (susceptible) embryo no. 156 regenerants, but the level of resistance did not approach that exhibited by 'Nemaguard'. Increased levels of resistance were not observed among 'Redhaven' (moderately resistant) embryo no. 30 regenerants; however, only regenerants from a single embryo of 'Sunhigh' and a single embryo of 'Redhaven' were studied, which may account for the lack of increased resistance in regenerants derived from 'Redhaven' embryo callus. Thus, in future studies, regenerants from many genotypes (embryos) of 'Redhaven' should be evaluated. In addition, recent in vitro and microplot studies by Huettel and Hammerschlag (1993) reported high levels of root-knot resistance (but not as high as 'Nemaguard') in 'Compact Redhaven' peach, which, together with compact growth habit and cold tolerance (Van Well, 1974), makes it an even better candidate than 'Redhaven' for somaclonal variation studies.

Although some studies have indicated that in vitro culture may increase susceptibility to root-knot nematode (Dropkin et al., 1969; Fassuliotis, 1990; Fassuliotis and Bhatt, 1982), other studies have provided evidence of the stability of root-knot nematode resistance in Lycopersicon sp. (Ammati et al., 1984) and peach (Huettel and Hammerschlag, 1986, 1993). Ammati et al. (1984) suggested that some tissue culture conditions can enhance the expression of symptoms associated with nematode infection, such as gall development. Support for this hypothesis is provided by previous studies in which seedling roots of nematode-resistant tomato (Dropkin et al., 1969) and peach (Kochba and Samish, 1971) developed galls and the nematodes produced eggs when the roots were treated with high doses of cytokinin. Studies with other nematode species (Webster and Lowe, 1966) also suggest that hormones can influence nematode development by influencing plant growth in vitro. Thus, the stability of resistance to $M$. incognita observed in this study and previous studies (Huettel and Hammerschlag, 1986, 1993) may result fromusing a tissue-culture medium without supplemental phytohormones.

Distinct differences in nematode development and in growth characteristics (shoot and root weight) were evident among nematode-infected no. 156-series regenerants under in vitro conditions. Of the growth characteristics, only root weights of infected plants were useful in categorizing the regenerants. Root fresh weights of SH-156-1 and SH-156-11 were significantly different from 'Sunhigh', whereas root weights of SH-156-7 and SH-156-12 were similar to 'Sunhigh'. These same trends held up when comparing the average number of females in the root systems of all the no. 156-series regenerants, except for SH-156-12. The results relating to shoot height are not surprising, since previous studies showed no effect of nematodes on peach tree diameter and yield under microplot conditions until 3 to 4 years after planting (Huettel and Hammerschlag, 1993). The latter study (Huettel and Hammerschlag, 1993) and the response of regenerant SH-156-12 point out the difficulty of establishing reliable parameters for in vitro screening and suggest that monitoring in vitro nematode counts and the weight of infected roots will probably be the most useful characteristics for predicting the *response to root-knot under field conditions. In most cases, increase in root weight following infection is due to gall formation, which is evident with the root weight increase exhibited by highly susceptible 'Sunhigh'. In the case of SH-156-12, the extensive root system of the uninfected controls suggests that root weight alone accounted for much of the weight of the infected roots and explains why this regenerant fell into an intermediate category rather than with 'Sunhigh' when monitoring nematode counts.

In vitro and in the greenhouse, the number of mature females developing on the roots of 'Sunhigh' was significantly different from the number developing on regenerants SH-156-1 and SH156-12. In contrast, regenerant SH-156-7 exhibited a response similar to 'Sunhigh' in vitro, but significantly different from 'Sunhigh' in the greenhouse. The discrepancy between results in the greenhouse and in vitro could result from the small sample size used in greenhouse experiments or the possibility that the in vitro assay was more sensitive.

Besides response to root-knot nematode, the significant differences in shoot and root weights and rooting among the no. 156series regenerants suggest that somaclonal variation for growth and development characteristics is present among 'Sunhigh' embryo no. 156 regenerants. Several other studies have described the phenotypic variation in morphological characteristics of regenerated plants, for example, growth habit and tuber uniformity in potato (Shepard et al., 1980) and alterations in plant height, shoot length, and number of primary branches in alfalfa (Reisch, 1983). Further studies on regenerant 156-1 need to be conducted to determine if reduced growth-in vitro translates to a more compact growth habit under greenhouse and field conditions.

The success of a crop-improvement program depends on the extent of genetic variability in the base population (Bajaj, 1990). The present study demonstrates that somaclonal variation and in vitro screening can be of value for increasing genetic variability and suggests that, in the future, peach-improvement programs should combine in vitro technologies and conventional breeding techniques.

\section{Literature Cited}

Ammati, M., T. Murashige, and I.J. Thomason. 1984. Retention of resistance to root-knot nematode, Meloidogyne incognita, by Lycopersicon plants reproduced through tissue culture. Plant Sci. Lett. 35:247250.

Bajaj, Y.P.S. 1990. Somaclonal variation -origin, induction, cryopreservation, and implications in plant breeding, p. 3-48. In: Y.P.S. Bajaj (ed.). Biotechnology in agriculture and forestry. Springer-Verlag, Berlin.

Berlyn, M.B. 1980. Isolation and characterization of isonicotinic acid hydrazide resistant mutants of Nicotiana tabacum. Theor. Applied Genet. 58: 19-26.

Burrows, P.R. and M.G.K. Jones. 1993. Cellular and molecular approaches to the control of plant parasitic nematodes, p. 609-630. In: K. Evans, D.L. Trudgill, and J.M. Webster (eds.). Plant parasitic nematodes in temperate agriculture. C.A.B. lntl., Wallingford.

Daub, M.E. 1986. Tissue culture and the selection of resistance to pathogens. Annu. Rev. Phytopathol. 24: 159-186.

Daub, M.E. and A.E. Jenns. 1989. Field and greenhouse analysis of variation for disease resistance in tobacco somaclones. Phytopathology 79:600-605.

Dropkin, V.H., J.P. Helgeson, and C.D. Upper. 1969. The hypersensitivity reaction of tomato resistant to Meloidogyne incognita: Reversal by cytokinin. J. Nematol. 1:55-56.

Evans, N.E., D. Foulger, L. Farrer, and S.W.J. Bright. 1986. Somaclonal variation in explant derived potato clones over three tuber generations. Euphytica 35:353-361.

Fassuliotis, G. 1990. Somaclonal variation for nematode resistance, p. 258-268. In: Y.P.S. Bajaj (ed.). Biotechnology in agriculture and forestry. Springer-Verlag, Berlin.

Fassuliotis G. and D.P. Bhatt. 1982. Potential of tissue culture for breeding root-knot nematode resistance into vegetables. J. Nematol. 14:10-14.

Gamborg, O.L., T.A. Thorpe, and I.K. Vasil. 1976. Plant tissue culture media. In Vitro 12:473-478.

Gavazzi, G., C. Tonelli, G. Todesco, E. Arreghini, F. Raffaldi, F. Vecchio, 
G. Barbuzzi, M.G. Biasini, and F. Sala. 1987. Somaclonal variation versus chemical induced mutagenesis in tomato (Lycopersicon esculenturn L.). Theor. Applied Genet. 74:433-438.

Hammerschlag, F.A. 1984. In vitro approaches to disease resistance, p. 453-490. In: G.B. Collins and J.G. Petolino (eds.). Applications of genetic engineering to crop improvement. Nijhoff/Junk, Dordrecht.

Hammerschlag, F.A. 1988. Selection of peach cells for insensitivity, to culture filtrates of Xanthomonas campestris pv. pruni and regeneration of resistant plants. Theor. Applied Genet. 76:865-869.

Hammerschlag, F.A. 1990. Resistant responses of plants regenerated from peach callus to Xanthomonas campestris pv. pruni. J. Amer. Soc. Hort. Sci. 115: 1034-1037.

Hammerschlag, F.A. 1992. Somaclonal variation, p. 35-55. In: F.A. Hammerschlag and R.E. Litz (eds.). Biotechnology of perennial fruit crops. C.A.B. Intl., Wallingford.

Hammerschlag, F.A. and V. Ognjanov. 1990. Somaclonal variation in peach: Screening for resistance to Xanthomonas campestris pv. pruni and Pseudomonas syringae pv. syringae. Acta Hort. 280:403-408.

Hammerschlag, F.A., G.R. Bauchan, and R. Scorza. 1985. Regeneration of peach plants from callus derived from immature embryos. Theor. Applied Genet. 70:248-251.

Hammerschlag, F.A., G.R. Bauchan, and R. Scorza. 1987. Factors influencing in vitro multiplication and rooting of peach cultivars. Plant Cell Tissue Organ Cult. 8:235-242.

Hammerschlag; F.A., D.J. Werner, and D.F. Ritchie, 1994. Stability of bacterial leaf spot resistance in peach regenerants under in vitro, greenhouse and field conditions. Euphytica 76:101-106.

Heath-Pagliuso, S., J. Pullman, and L. Rappaport. 1988. Somaclonal variation in celery: Screening for resistance to Fusarium oxysporum f.sp. apii, race 2. Theor. Applied Genet. 75:44-451.

Huettel, R.N. and F.A. Hammerschlag. 1986. Influence of cytokinin on in vitro screening of peaches for resistance to nematodes. Plant Dis. 70:248-251.

Huettel, R.N. and F.A. Hammerschlag, 1993. Response of peach scion cultivars and rootstocks to Meloidogyne incognita in vitro and in microplots. J. Nematol. 25:472-475.

Kochba, J. and R.M. Samish. 1971. Effect of kinetin and 1naphthaleneacetic acid on root-knot nematodes in resistant and susceptible peach rootstocks. J. Amer. Soc. Hort. Sci. 96:458-461.

Larkin, P.J. and W.R. Scowcroft. 1981. Somaclonal variation-A novel source of variability from cell cultures for plant improvement. Theor. Applied Genet. 60:197-214.

Larkin, P.J., L.H. Spindler, and P.M. Banks. 1990. Cell culture of alien chromosome addition lines to induce somatic recombination and gene introgression, p. 163-168. In: H.J.J. Nijkamp, L.H.W. van der Plas, and
J. van Aartrijk (eds.). Progress in plant cellular and molecular biology. Kluwer, Dordrecht.

Latunde-Dada, A.O. and J.A. Lucas. 1983. Somaclonal variation and reaction to Verticillium wilt in Medicago sativa L. Plants regenerated from protoplasts. Plant Sci. Lett. 32:205-211.

Layne, R.E.C. 1974. Breeding peach rootstocks for Canada and Northern United States. HortScience 9:364-366.

McClure, M.A., T.H. Kruk, and I. Misaghi. 1973. A method for obtaining quantities of clean Meloidogyne eggs. J. Nematol. 5:230.

McCoy, T.J., R.L. Philips, and H.W. Rines. 1982. Cytogenetic variation in tissue culture regenerated plants of Avena sativa: High frequency of chromosome loss. Can. J. Genet. Cytol. 24:37-50.

Murashige, T. and F. Skoog. 1962. A revised medium for rapid growth and bioassays with tobacco tissue cultures. Physiol. Plant. 15:473-497.

Reisch, B. 1983. Genetic variability in regenerated plants, p. 748-769. In: D.A. Evans, W.R. Sharp, P.V. Ammirato, and Y. Yamada (eds.) Handbook of plant cell culture. vol. 1. Macmillan, New York.

Ritchie, D.F. and C.N. Clayton. 1981. Peach tree short life-A complex of interacting factors. Plant Dis. 65:462-469.

Ritchie, D.F., F.A. Hammerschlag, and D.J. Werner. 1993. Field evaluation of tissue culture-derived peach trees for susceptibility to bacteria spot (Xanthomonas campestris pv. pruni). Acta Hort. 336: 155-160.

Scorza, R. and F.A. Hammerschlag. 1992. Stone fruits, p. 277-301. In: F.A. Hammerschlag and R.E. Litz (eds.). Biotechnology of perennial fruit crops. C.A.B. Intl., Wallingford.

Scorn, R. and W.R. Okie. 1991. Peaches (Prunus). Acta Hort. 290:175-231.

Sharpe, R.R., P.L. Pusey, A.P. Nyczepir, and W.J. Florkowski. 1993. Influence of soil fumigation, rootstocks and time of pruning on peach yield and economics in peach tree short life orchards. J. Prod. Agr. 6:241-244.

Shepard, J., D. Bidney, and E.A. Shahin. 1980. Potato protoplasts in crop improvement. Science 208: 17-24.

Sherman, W.B., P.M. Lyrene, and P.E. Hansche. 1981. Breeding peach rootstocks resistant to root-knot nematodes. HortScience 16:523-524.

Thomas, E. 198 1. Plant regeneration from shoot culture-derived protoplasts of tetraploid potato (Solanum tuberosum cv. 'Maris Bard'). Plant Sci. Lett. 23:81-88.

Van Well, R.G. 1974. Compact Redhaven. Fruit Var. J. 28:37.

Webster, J.M. and D. Lowe. 1966. The effect of the synthetic plant growth substance, 2,4-dichlorophenoxyacetic acid, on the host-parasite relationship of some plant parasitic nematodes in monoxenic callus culture. Parasitology 56:313-322.

Wright, J.C. and M.L. Lacy. 1988. Increase in disease resistance in celery cultivars by regeneration of whole plants from cell suspension cultures. Plant Dis. 72:256-259. 